\title{
Peertechz
}

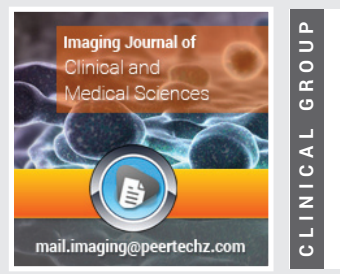

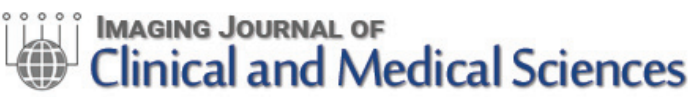

Clinical Image

\section{Exclusive Image Gallery on Human Spinal Cord Regeneration}

\section{Giselher Schalow*}

MD, PhD, Untere Kirchmatte 6, CH-6207 Nottwil, Switzerland

Received: 22 May, 2019

Accepted: 15 June, 2019

Published: 16 June, 2019

*Corresponding author: Giselher Schalow, Professor, Untere Kirchmatte 6, CH-6207 Nottwil, Switzerland, E-mail: g_schalow@hotmail.com

https://www.peertechz.com

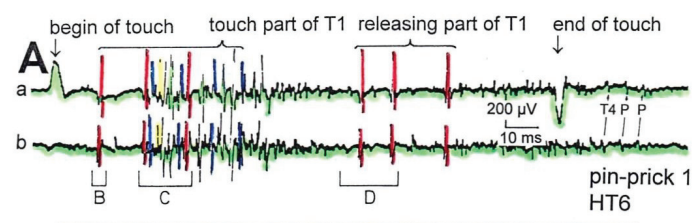

Touch (and pain) - stimulated afferent activity
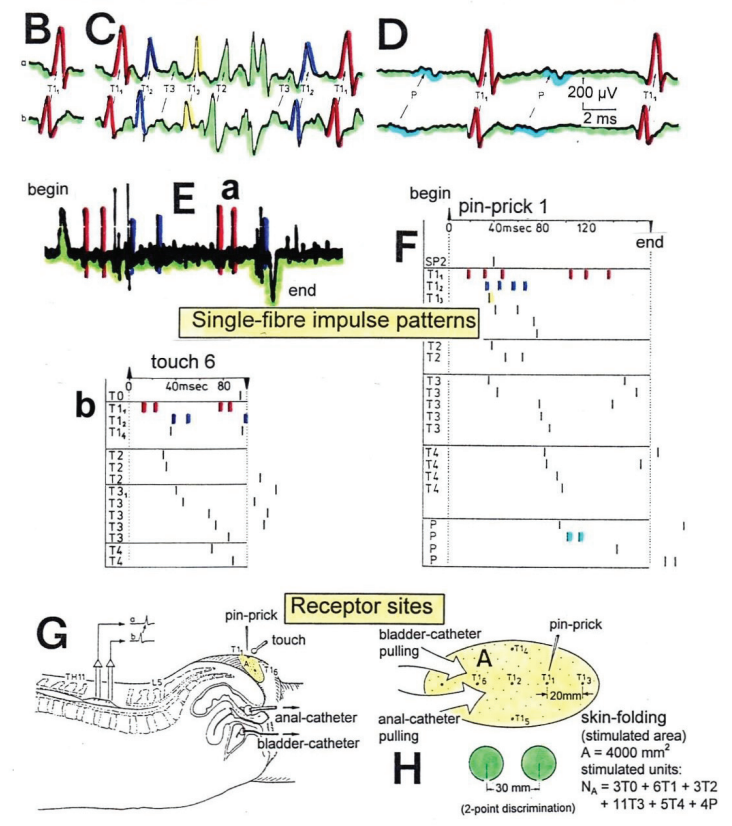

Figure 10: Touch (and pain)-stimulated afferent activity. Touch and pain activity, stimulated by pin-prick (A) and touch (Ea) of S5 or Co dermatomes and recorded extracellularly from a dorsal coccygeal root (brain-dead human HT6). T1, T2, T3, T4, P = mark action potentials (APs) from single touch and pain fibers. Subscripts 1, 2, 3 mark single fibers.

Copyright: (C) 2019 Schalow G. This is an open-access article distributed under the terms of the Creative Commons Attribution License, which permits unrestricted use, distribution, and reproduction in any medium, provided the original author and source are credited. 